\title{
Materialismo e consumo de produtos de luxo falsificados
}

\author{
Materialism and luxury goods consumption fake
}

\author{
Pablo Marlon Medeiros da Silva ${ }^{1}$ \\ Juliana Carvalho de Sousa ${ }^{2}$ \\ Aline Francilurdes Nery do Vale ${ }^{3}$ \\ Bruna Lourena de Lima Dantas ${ }^{4}$ \\ Francisca Noeme Moreira de Araújo ${ }^{5}$
}

\begin{abstract}
Resumo
A procura por bens luxuosos tem sido cada vez mais crescente. Seu mercado encontra-se em ascensão, atraindo a atenção de empresas e pesquisadores para o materialismo, como também para o problema da falsificação desses produtos. 0 objetivo desse trabalho é investigar a relação entre o materialismo e o consumo de produtos falsificados em consumidores de cidades do estado do Rio Grande do Norte. Sendo a pesquisa de natureza descritiva e explicativa, com abordagem quantitativa, utilizou-se neste estudo o questionário de materialismo propostos por Richins e Dawson (1992), e o de compra de produtos falsificados, elaborado por Wilcox et al. (2009) e validado por Queiroz (2014), os quais foram aplicados a 615 consumidores. A pesquisa mostrou que houve correlação entre o materialismo e o consumo de produtos de luxo falsificados, como também revelou que as mulheres apresentaram maiortendência materialista do que os homens, assim como os indivíduos que possuem nível superior, os consumidores pertencentes às classes $\mathrm{C}$ e D e as pessoas solteiras foram as categorias mais representativas no que tange ao materialismo. Em relação ao consumo de produtos falsificados, o gênero feminino, os indivíduos solteiros, as pessoas com nível superior e aqueles que recebem entre três e seis salários mínimos foram os que mais apresentaram tendências a esse tipo de consumo. $\mathrm{O}$ artigo traz contribuições à teoria e pode auxiliar as organizações a adotarem estratégias para alcançar diferentes segmentos de mercado para o consumo de bens de luxo, como também a prevenirem a falsificação de seus produtos, evitando perdas financeiras e outras consequências.
\end{abstract}

Palavras chave: Materialismo. Consumo. Produtos falsificados. Luxo. Mercado.

\begin{abstract}
The demand for luxury goods has been increasing. Its market is on the rise, attracting the attention of companies and researchers to materialism, as well as to the problem of the falsification of these products. The objective of this work is to investigate the relationship between materialism and the consumption of counterfeit products in consumers of cities in the state of Rio Grande do Norte. The research was descriptive and explanatory, with a quantitative approach, and the questionnaire of materialism, proposed by Richins and Dawson (1992) and the purchase of counterfeit products, prepared by Wilcox et al. (2009) and validated by Queiroz (2014), which were applied to 615 consumers. The research showed that there was a correlation between materialism and the consumption of fake luxury products, but also revealed that women presented higher materialistic tendencies than men, as well as individuals with higher education, consumers belonging to classes $C$ and $D$ and single persons Were the most representative categories when it came to materialism. In relation to the consumption of counterfeit products, the female gender, single individuals, people with a higher level and those who receive between 3 and 6 minimum wages were the ones that presented the most tendencies to this type of consumption. The article brings contributions to the theory and can help organizations to adopt strategies to reach different market segments for the consumption of luxury goods, as well as prevent the falsification of their products, avoiding financial losses and other consequences.
\end{abstract}

Keywords: Materialism. Consumption. Forged products. Lux. Marketplace.

Doutorando em Administração pela Universidade Potiguar - UNP. Brasil. Afiliação: Universidade Potiguar. Lattes: http://lattes.cnpq. br/2530048436665066 Email: pablo_marlon17@hotmail.com

2 Mestre em Administração pela Universidade Estadual do Ceará - UECE. Brasil. Afiliação: UECE. Lattes: http://lattes.cnpq.br/2002557867629902 Email: juli_carvalho18@hotmail.com

3 Graduada em Administração pela Universidade Federal Rural do Semi Árido - UFERSA. Afiliação: UFERSA. Lattes: http://lattes.cnpq. br/9569603262730657 Email: alinefrancilurdes@hotmail.com

Mestranda em Administração pela Universidade Federal de Paraíba - UFPB. Brasil. Afiliação: UFPB. Email: brunalima.adm@hotmail.com

5 Mestre em Administração pela Universidade Potiguar - UNP. Brasil. Afiliação: UNP. Lattes: http://lattes.cnpq.br/3746414018942928 Email: noeme_moreira@hotmail.com 


\section{Introdução}

O materialismo é um conceito que muitas vezes é ligado a questões de satisfação, bem-estar e felicidade (LEE; AHN, 2016). Identifica-se predominantemente com o consumo, permitindo analisar a noção de relevância que um indivíduo atribui à posse e à crença de que a compra de produtos luxuosos é a melhor fonte de felicidade e satisfação que ele pode ter na vida (RICHINS; DAWSON, 1992).

A prevalência e o aumento do consumo de bens luxuosos por parte dos indivíduos têm despertado interesse em vários grupos no mercado global. Para as organizações, um melhor entendimento do motivo pelo qual as pessoas valorizam suas posses lhes proporcionará a adoção de medidas para servir melhor seus usuários por meio da gestão do mix de marketing, visando maximizar valor para o cliente e gerar bons resultados para a empresa (OGDEN; CHENG, 2011).

Além do materialismo, as preocupações de empresas e dos pesquisadores também se voltam para o crescimento do consumo da contrafação, ou seja, da falsificação de produtos. Um estudo realizado pelo SPC Brasil e Meu Bolso Feliz (2015) mostrou que, a cada dez pessoas, pelo menos sete garantiram já ter adquirido produtos de marca não originais. Dentre eles, destacam-se: roupas (39\%), acessórios (24\%), calçados (22\%), eletrônicos (17\%) e perfumes (14\%). A maior parte da demanda de produtos contrafeitos está entre os mais jovens, pertencentes à classe $\mathrm{C}$ e de baixa escolaridade. Com relação à idade, entre os consumidores com idade até 34 anos, por exemplo, $50 \%$ afirmam já ter comprado roupas de marca não originais, contra $25 \%$ entre os mais velhos, a partir dos 55 anos. Nesse contexto, surge a seguinte questão norteadora: qual a relação entre materialismo e consumo de produtos falsificados?

O objetivo deste trabalho é investigar a relação entre o materialismo e o consumo de produtos falsificados em consumidores de cidades do estado do Rio Grande do Norte. O estudo se torna relevante pela representatividade que os bens de luxo possuem para a economia mundial e nacional, mostrando que o setor movimentou $€ 223$ bilhões somente em 2014, destacando-se os mercados europeus (34\%) e o americano (32\%), segundo dados da Bain e Company (2014). Já no Brasil, a venda de produtos de luxo triplicou nos últimos anos, alcançando 20,7 bilhões de reais em 2012, de acordo com estimativas da revista Exame (2012). Para a ciência, esse artigo é capaz de fornecer amadurecimento teórico e empírico por se tratar de um tema ainda pouco explorado no Brasil. Já para as organizações, proporcionará informações que podem levá-las a refletir sobre a adoção de estratégias que para alavancar seus negócios, alcançando diferentes públicos no mercado, bem como amenizar os efeitos da falsificação de produtos, responsáveis por gerar perdas financeiras, dentre outros aspectos, para as empresas, para o Estado e para a sociedade.

\section{Referencial teórico}

\subsection{0 consumo de bens de luxo e o materialismo}

O primeiro grande desafio para estudar o mercado de luxo incide em compreender o conceito de luxo. Etimologicamente, a palavra luxo vem de lux, que em latim significa luz, indicando também luminosidade e brilho. Ferreira et al. (2013) definem luxo como algo exclusivo, singular, raro e difícil de ser encontrado. Hennings, Wiedmann e Klarmann (2012) destacam o fator exclusividade como sendo a "característicachave" de qualquer produto de luxo, juntamente com acessibilidade limitada e raridade, de forma que tais elementos são cruciais para justificar seu alto preço.

Embora existam pesquisas abordando o comportamento materialista, muitos autores ainda não chegaram a uma definição genérica sobre o tema. Para Turkylmaz, Uslu e Durmus (2015), o materialismo está ligado à importância que o consumidor atribui aos bens materiais, como estão ligados a sua satisfação, bem-estar, prazer, felicidade, sucesso e realização pessoal. Indo além desse conceito, Santos e Fernandes (2011) afirmam que o materialismo é uma atitude que abrange traços relacionados à personalidade do consumidor, como possessividade, inveja, insegurança, pouca generosidade. Ademais, o consumidor materialista considera que seu bem-estar depende da posse de bens materiais. 
Já Richins e Dawson (1992) definem o materialismo como o desejo de adquirir e possuir bens materiais a fim de alcançar propósitos e estados desejados na vida, levando o indivíduo a três tipos de orientação: centralidade de aquisição; a posse como busca da felicidade, e o sucesso definido pelo poder.

Segundo Nogami e Garbim (2014), os produtos de luxo abrangem fatores racionais de compra, como originalidade e qualidade, e também fatores irracionais, como distinção social e status. Mas as finalidades da utilização de bens de luxo podem ser explicadas de acordo com os tipos de consumidores existentes. Dentre os tipos de consumidores de bens de luxo, estão os que desejam ostentar, ou seja, impressionar os outros; os que desejam se igualar, e, por isso, compram produtos que outras pessoas possuem; os que desejam ser únicos e são influenciados pelos fatores emocionais; os que desejam a perfeição, isto é, que procuram no produto uma qualidade superior; os hedonistas, que desejam vivenciar uma experiência prazerosa com o uso de bens de luxo; e, por fim, os de gosto refinido, que entendem, avaliam e apreciam o uso de artigos de luxo em diversos contextos.

A literatura mostra que nem sempre os indivíduos percebem os estímulos que os tornam consumistas, e esse fato pode levá-los a adotar comportamentos incontroláveis, que, por sua vez, podem gerar efeitos negativos em sua vida e das pessoas que os cercam (SCHUSTER; DIAS; BATTISTELLA, 2016). Por exemplo, Kasser (1992) argumentou que indivíduos extremamente materialistas tendem a ter menor bem-estar e saúde mental em comparação àqueles que não são. Consequentemente, problemas como infelicidade, insatisfação na vida, depressão, ansiedade, frieza e indiferença no tratamento das outras pessoas podem surgir conforme predomina o desejo compulsivo. Estudos mostram que consumidores materialistas têm mais dificuldades em compartilhar o que possuem em termos de bem e riquezas (JOUNG, 2013), estão mais propensos a adquirir comportamentos de compra antiéticos (KOZAR; MARCKETTI, 2011), a possuírem visões mais negativas acerca das instituições de caridade e a serem insensíveis no auxílio a amigos e familiares, além de preferirem gastar mais consigo que com os outros (RICHINS; DAWSON, 1992). Nessa perspectiva, Veer e Shankar (2011) acreditam que o materialismo é negativo quando o consumidor coloca a aquisição de bens no centro de sua vida, como motivo principal para conquistar a felicidade.

Kasser (1992) aborda que o sacrifício pessoal da redução dos valores materialistas é uma das únicas estratégias para enfrentar os problemas advindos do materialismo, aumentando a qualidade de vida do indivíduo, de sua família e da comunidade de forma geral. Apesar do forte crescimento do consumo de bens materiais, Belk (2013) ressalta que alguns dos produtos consumidos hoje estão passando por um processo de "desmaterialização", em que as informações estão passando de bens físicos a fluxos eletrônicos que podem ser armazenados em nuvens dentro da internet. Um exemplo disso é a substituição de livros, CDs, DVDs, que antes podiam ser manipulados e organizados, pelo armazenamento digital. Porém, $\mathrm{O}$ autor entende, porém, que muito há a ser explorado ainda acerca do assunto a fim de que essa tendência possa ser confirmada em grande parte dos produtos.

\subsection{Falsificação de artigos de luxo}

Um aspecto mundial que tem crescido num ritmo alarmante nas últimas décadas é a produção, distribuição e consumo de produtos falsificados (NORUM; CUNO, 2011). A falsificação tem lançado desafios para grandes empresas de marcas, implicando em uma concorrência intramarca, pois os empresários não estão apenas competindo com outras no mercado, mas também enfrentam problemas com as cópias de seus próprios produtos (BIAN; MOUTINHO, 2011).

Para Chaudhry e Stumpf (2011, p.140), falsificação de produtos é "qualquer produção não autorizada ou distribuição de bens cujas características especiais são protegidos mediante direitos de marcas, patentes e copyrights". Já a World Trade Organization (WTO, 2014) a define como cópias não autorizadas de uma marca registrada de forma a tornar um produto parecido com um bem produzido pela marca a fim de induzir clientes a adquirir produtos acreditando que são originais.

Estudos têm mostrado que diversos fatores têm influenciado o comportamento de consumidores a adquirir produtos falsificados, entre eles estão os benefícios econômicos e as caraterísticas socioeconômicas e demográficas. Entre os produtos mais falsificados, destacam-se: os farmacêuticos, automotivos, eletrônicos e aeroespaciais (DODGE et al., 1996; NORUM, CUNO, 2011; STEVENSON, BUSBY, 2015). 
Embora seja dificil mensurar com exatidão o tamanho do prejuízo causado pela falsificação de produtos, o Counterfeit Intelligence Bureau (CIB, 2011) estima que o problema atinja entre 5 a $7 \%$ do comércio mundial, o que representa cerca de 600 bilhões de dólares por ano. De acordo com Stevenson e Busby (2015), as consequências da contrafação é a redução de receitas fiscais, o aumento do terrorismo e do crime organizado, e o crescimento da desconfiança por parte dos consumidores, dentre outros.

Antigamente as falsificações de produtos originais eram de fácil reconhecimento, devido a diferenças na aparência e menor qualidade em termos de durabilidade, confiabilidade e desempenho. Ao longo dos anos isso tem mudado, e as diferenças estão cada vez mais imperceptíveis (TURUNEN; LAAKSONEN, 2011). Em relação ao consumo, existem, na visão de Grossman e Shapiro (1988), dois tipos de práticas na aquisição de produtos falsificados: a falsificação enganosa, em que os consumidores não conseguem distinguir com facilidade cópias de produtos legítimos e, por isso, adquirem produtos contrafacionados sem conhecimento; e, por outro lado, existe a contrafação não enganosa. Nesse caso, as pessoas que compram produtos falsificados o fazem com conhecimento de causa. Norgami e Garbim (2014) reforçam esse entendimento quando afirmam que os consumidores entendem que o produto é falsificado, tanto pelo preço cobrado quanto pelo local onde ele está sendo vendido. Assim, com um preço inferior aos de produtos originais, um produto falsificado torna-se atraente aos consumidores (SILVA; PESSOA; OLIVEIRA, 2013).

De acordo com pesquisas feitas pelo SPC Brasil e Meu Bolso Feliz (2015), a maior incidência de compra de itens não originais é observada na classe C (44\%), enquanto se afunila nas classes ascendentes ( $28 \%$ na classe $B$ e $24 \%$ na Classe A) dos respondentes; entre indivíduos que possuem segundo grau incompleto, o percentual é de $48 \%$, contra $32 \%$ entre os respondentes com ensino superior completo. Dos investigados, $31 \%$ afirmaram nunca ter adquirido algum produto não original.

Como a compra de produtos não originais é uma atividade de consumo atrelada ao prestígio da marca e da imagem, parece aceitável, então, que exista uma relação entre o materialismo e o comportamento de compra de bens de produtos falsificados (KOZAR; MARCKETTI, 2011). Dessa maneira, foram formuladas as seguintes hipóteses:

- H1: As variáveis gênero, faixa etária, renda, escolaridade, e estado civil contribuem para o índice de materialismo;

- H2: As variáveis gênero, faixa etária, renda, escolaridade, e estado civil contribuem para o consumo de produtos de luxo falsificado;

• H3: Há associação entre o materialismo e o consumo de produtos de luxo falsificados.

A próxima seção apresenta os aspectos metodológicos que serviram de norte para a consecução do objetivo da pesquisa.

\section{Metodologia}

A presente pesquisa se caractertiza como um estudo de caráter quantitativo. Em relação à natureza da pesquisa, pode-se classificá-la como descritiva e explicativa. Explicativa por verificar a existência de relações entre as variáveis em questão; e descritiva por procurar aprofundar o conhecimento sobre a natureza dos fenômenos (VERGARA, 2013).

Para a coleta de dados, utilizou-se de dois instrumentos: as escalas de materialismo e a de produtos de luxo falsificados. Os construtos e as variáveis de análise usados para medir o materialismo foram elaborados por Richins e Dawson (1992). No Brasil, o questionário foi aplicado nas pesquisas de Moura et al. (2006) e Santos (2012), efetivando a validação da escala (QUEIROZ, 2014).

O construto materialismo, proposto por Richins e Dawson (1992), é composto por três dimensões: centralidade, felicidade e sucesso. A dimensão "centralidade" avalia a indicação da posição das posses e aquisições na vida das pessoas. Já para medir a dimensão "felicidade", observa-se até que ponto as posses proporcionam felicidade e bem-estar pessoal ao indivíduo. Por conseguinte, para mensurar a dimensão "sucesso", analisa-se a tendência de um indivíduo em julgar os outros e a si mesmo em função da quantidade e qualidade de suas posses, olhando o sucesso a partir dos bens acumulados. 
Com relação ao segundo instrumento de pesquisa, que se trata da escala para medir os motivos do consumo de produtos de luxo falsificados, foi elaborada por Wilcox et al. (2009), validada por Queiroz (2014) e subdivide-se em dois construtos: função expressiva de valor e função de ajustamento social.

É importante destacar que, além das escalas acima citadas, a pesquisa envolveu questões acerca dos dados demográficos dos respondentes. Dessa forma, a pesquisa é do tipo survey. Segundo Gil (2010), a pesquisa survey compreende um levamentamento de dados em uma amostra significativa a fim de obter conclusões a respeito dos dados analisados.

A pesquisa foi operacionalizada com indivíduos residentes em três cidades do estado do Rio Grande do Norte (Mossoró, Natal e Areia Branca). Tendo como universo uma população desconhecida, a amostra foi calculada com base na fórmula da primeira aproximação, apresentada por Barbetta (2004):

$$
n_{0}=\frac{1}{E^{2}}
$$

Sendo:

- $n_{0}=$ primeira aproximação do tamanho da amostra;

- $E$ = erro amostral tolerável

Dada a natureza da pesquisa, foi admitido um erro amostral $(E)$ de $5 \%, 0,05$. Nesse caso, utilizandose a fórmula de primeira aproximação da amostra, seria necessária a aplicação de uma quantidade mínima de 400 questionários. Para fins dessa pesquisa, foram obtidos 615 questionários respondidos.

A coleta de dados foi realizada de forma on-line, nos meses de abril e maio de 2016, na qual divulgouse o link para acesso por intermédio das principais redes sociais, como Facebook, Instagram, Twitter, dentre outras. Esse método é caracterizado por Mattar (2008) como um questionário auto-preenchido, em que o pesquisado lê o instrumento e o responde diretamente, sem a intervenção do pesquisador. Os dados foram tratados no software Statistical Package for the Social Sciences, versão 20.0, fazendose o uso de módulos de estatística descritiva, análise de variância (ANOVA) e correlação de Pearson. A estatística descritiva foi utilizada para apuração da frequência de respostas às questões formuladas, dados demográficos e percepção dos respondentes. O uso da ANOVA justificou-se por ser o teste estatístico mais adequado para testar as hipóteses estabelecidas na pesquisa, e a correlação auxiliou no alcance do objetivo geral do trabalho.

\section{Resultados e discussões}

Com relação à caracterização dos indivíduos que participaram da pesquisa, a maior parte está concentrada na cidade de Mossoró (73,2\%), sendo seguida por Areia Branca (7,6\%) e, por último, Natal $(5,1 \%)$. A maioria pertence ao gênero feminino $(67,8 \%)$. Com relação à faixa etária: $17,6 \%$ possuem até 20 anos; $59,4 \%$ possuem de 21 a 30 anos; $14,6 \%$ de 31 a 40 anos; $5,3 \%$ de 41 a 50 anos, e 3,0\% mais de 50 anos de idade. Quanto ao estado civil: $62,2 \%$ são solteiros; $32,8 \%$ são casados ou possuem relação estável; 3,9\% são divorciados ou separados, e $0,8 \%$ são viúvos.

No que tange à escolaridade dos investigados: 1,3\% possui apenas nível fundamental; $28,7 \%$ possuem nível médio; $47,1 \%$ nível superior; $17,7 \%$ especialização; 4,3\% mestrado e $0,7 \%$ doutorado. Sobre a ocupação desses indivíduos: $38,1 \%$ são estudantes; $25,8 \%$ são empregados com carteira assinada; $11 \%$ são autônomos; $17,6 \%$ são concursados e $7,4 \%$ são desempregados. Sobre a renda familiar: $35,6 \%$ ganham até dois salários mínimos; $44,8 \%$ ganham de três a seis salários mínimos; $12,2 \%$ ganham de sete a dez salários mínimos, e 7,2\% recebem mais de dez salários mínimos.

Quando investigado se os respondentes consumiam produtos de luxo falsificados, obteve-se que: $10,7 \%$ afirmaram que sim; $50,7 \%$ às vezes, e $38,6 \%$ que não consumiam. Dentre os tipos de produtos falsificados informados, estão: bolsas (2\%); roupas (5,6\%); calçados $(7,7 \%)$; perfumes $(13,3 \%)$, e jóias $(45,8 \%)$. 
A fim de testar a H1 (As variáveis gênero, faixa etária, renda, escolaridade, e estado civil contribuem para o índice de materialismo), procedeu-se à ANOVA com cada variável sociodemográfica isoladamente e com as variáveis que compõem a escala de materialismo. Quando analisado se o gênero influencia, obtevese os seguintes resultados: "Geralmente compro apenas aquilo de que preciso" $(p=0,022)$; "Comprar objetos me dá um imenso prazer" ( $p=0,034)$; "Gosto de muito luxo na minha vida" $(0,026)$; "A minha vida seria melhor se eu possuísse coisas que eu não tenho" $(p=0,004)$; "Seria mais feliz se tivesse dinheiro para comprar mais coisas" ( $p=0,001)$; "Alguns dos feitos mais importantes na minha vida incluem os bens materiais" $(0,021)$. É importante ressaltar que foram considerados significativas todas as variáveis que apresentaram $p$-value inferior a 0,05.

Ao realizar a estatística descritiva, método tabela cruzada (cross tabulation), identificou-se que, nas variáveis significativas encontradas, o gênero feminino se sobressai em todas, exceto na última variável: "Alguns dos feitos mais importantes na minha vida incluem os bens materiais", na qual os homens apresentam-se em destaque. Logo, isso permite inferir que, dentre os entrevistados, as mulheres possuem mais tendência materialista do que os homens. Esses números permitem pressupor que as mulheres têm mais interesse no assunto de compras. Por serem mais suscetíveis a aspectos externos, elas parecem possuir maior vaidade, o que as conduz a adquirirem produtos de luxo, como roupas, bolsas, maquiagem, perfume, dentre outros, que venham a proporcionar-lhes satisfação e bem-estar com sua estética e vestimenta.

De acordo com Grohmann et al. (2011), o gênero é uma variável importante na compreensão do comportamento do consumidor. Um estudo realizado pelos mesmos autores, em 2011, com 390 consumidores brasileiros, apontou que a relação entre materialismo e importância atribuída à marca é mais forte no gênero feminino, enquanto que a relação entre materialismo e compra compulsiva é mais forte nos homens. Quanto às mulheres, as ações de mercado sugeridas pelos autores, portanto, deverim estar focadas na marca dos produtos. Já pra homens, a inovação de um bem seria um forte fator para incentivar sua compra compulsiva.

Com relação à faixa etária, os resultados foram os seguintes: "Tento manter a minha vida simples no que diz respeito aos meus bens materiais" ( $p=0,047)$; "Gosto de gastar dinheiro em coisas que não são necessárias" ( $p=0,003)$; "A minha vida seria melhor se possuísse coisas que eu não tenho" $(0,050)$; "Seria mais feliz se tivesse dinheiro para comprar mais coisas" $(0,003)$; "Às vezes, entristeço-me por não poder comprar todas as coisas que quero" $(0,000)$; "Admiro pessoas que possuem carros, casas e roupas caras" (0,027); "Não dou muita importância à quantidade de objetos materiais que as pessoas têm" $(0,001)$; "Gosto de ter coisas que impressionam as pessoas" $(0,022)$; "Não dou muita importância aos objetos materiais que os outros têm" $(0,004)$.

Destaca-se que, ao realizar a estatística descritiva, o método tabela cruzada (cross tabulation) identificou nas variáveis significativas encontradas, com relação à faixa etária, que os indivíduos entre 21 a 30 anos se sobressaíram em todas as variáveis analisadas, o que significa dizer que, com relação ao materialismo, esses indivíduos têm maior predisposição para apresentar condutas materialistas. Resultados semelhantes foram apresentados por Richins e Dawson (1992), mostrando que os jovens parecem se importar mais com a aquisição de posses do que os adultos. Esse fato pode ser justificado pelas peculiaridades que essa faixa etária possui. O comportamento e as atitudes dos jovens diferem dos de adultos, pois, por em muitas situações ainda estarem solteiros, morando com os pais, fazendo faculdade e provavelmente no início da carreira profissionai, levam uma vida de maneira mais ousada, com menos compromissos, buscando sempre seguir a moda do momento. Dessa forma, enxergam no consumo de bens de luxo uma maneira de diferenciar-se dos demais e atrair a atenção dos grupos aos quais estão inseridos. O consumo materialista, portanto, torna-se uma realidade presente nesses indivíduos.

No que concerne à renda, as seguintes variáveis mostram-se significativas: "Tento manter a minha vida simples no que diz respeito aos meus bens materiais" $(p=0,020)$; "Seria mais feliz se tivesse dinheiro para comprar mais coisas" ( $p=0,031)$; "Às vezes, entristeço-me por não poder comprar todas as coisas que quero" ( $p=0,003)$; "Alguns dos feitos mais importantes na minha vida incluem os bens materiais" $(p=$ $0,022)$. 
As evidências mostram que os indivídos que possuem renda de três a seis salários mínimos (classes C e D) tendem a ser mais materialistas, corroborando com a afirmação de Wang (2016), que mostra que a ambição por um estilo de vida mais moderno e luxuoso é uma tendência que vem afetando fortemente o comportamento de consumo dos grupos que compõem essa faixa salarial. Esse achado pode ser explicado pelo fato desse público estar buscando, cada vez mais, uma reconstrução de sua identidade social apoiada no consumo. As políticas de incentivo que o governo federal tem gerado nos últimos anos - por exemplo: o aumento do crédito, a redução do IPI, os financiamentos com taxa de juros mais baixas, dentre outras -, têm facilitado a aquisição de inúmeros produtos, que antes eram mais acessíveis aos consumidores de classes mais elevadas. Parece haver, por isso, uma influência maior sobre indivíduos com renda mais baixas para a compra além de suas necessidades. Santos e Fernandes (2011, p.173) explicam que esse comportamento pode levar a uma "busca excessiva de status por meio de posses, ao sentimento de inveja, de desconsideração do outro e da subjetividade do indivíduo, autocentralidade, possessividade, insegurança, falta de princípios e de valores morais".

Com relação à escolaridade, a variável significativa foi: "Às vezes, entristeço-me por não poder comprar todas as coisas que quero" ( $p=0,019)$. Realizando-se a estatística descritiva mediante o método da tabela cruzada, obteve-se que os indivíduos que possuem nível superior possuem maior tendência para entristecerem-se por não poder comprar os produtos de seu desejo. Um dos motivos que podem explicar tal resultado é que muitos estudantes iniciam a faculdade com grandes expectativas de sucesso, que, ao finalizarem o seu curso superior, estarão bem encaminhados para ter uma carreira bem-sucedida. Quando esses desejos são frustrados ao findar do curso, porém, esses estudantes acabam enxergando outra realidade, em que, a partir de agora, terão que se juntar a milhares de brasileiros desempregados no mercado de trabalho, e veem que diplomas de nível superior obtidos não mais garantem um futuro, como em décadas atrás. Quanto maior a escolaridade de um indivíduo, portanto, mais propensa será sua tristeza ao ver que o seu diploma não te trouxe benefícios financeiros para ter um poder aquisitivo maior para adquirir bens de luxo.

Sobre o estado civil, destacam-se as variáveis: "Tento manter a minha vida simples no que diz respeito aos meus bens materiais" ( $p=0,012)$ e "Seria mais feliz se tivesse dinheiro para comprar mais coisas" $(p=$ 0,001 ). A tabela cruzada mostra que indivíduos solteiros, possuem maior predisposição para levar uma vida simples no que tange aos bens materais. Talvez, o fato de muitas pessoas que se enquadram nesse grupo ainda serem jovens, dependentes financeiramente dos pais, ou até mesmo estarem em início de carreira, recebendo apenas o básico para as suas necessidades cotidianas, sejam fatores que expliquem esse comportamento. Os resultados também mostram, no entanto, que esse público, apesar de ser consciente do poder aquisitivo que possui, seria mais feliz e satisfeito se tivesse condições para usufruir de uma maior capacidade aquisitiva, que atendesse aos anseios que grande parte dos solteiros desejam, que é de se diferenciar e destacar na sociedade.

A fim de testar a hipótese H2 (As variáveis gênero, faixa etária, renda, escolaridade e estado civil contribuem para o consumo de produtos de luxo falsificado), procedeu-se novamente à ANOVA. Com relação à faixa etária, não se obteve nenhuma variável significativa. Achados de Queiroz (2014), entretanto, demonstraram que o consumo de produtos falsificados independe da idade de um indívuo, surgindo a partir do seu poder de compra, ou seja, parece inexistir correlação entre idade e contrafação de produtos.

Tratando-se do gênero, os resultados mostraram o seguinte: "As marcas de luxo refletem o tipo de pessoa que quero ser" ( $p=0,000)$; "As marcas de luxo me ajudam a me comunicar com a minha autoidentidade" ( $p=0,000)$; "As marcas de luxo ajudam a me definir" ( $p=0,004)$; "As marcas de luxo me ajudam a me enquadrar em situações sociais importantes" ( $p=0,012)$; "Eu gosto de ser visto usando marcas de luxo" ( $p=0,006)$; "Eu gosto de quando as pessoas sabem que eu estou usando uma marca de luxo" $(p=0,026)$. E com relação à renda, a variável que se destacou foi: "Eu gosto de ser visto usando marcas de luxo" ( $p=0,025)$.

Para as variáveis "as marcas de luxo refletem o tipo de pessoa que quero ser" e "as marcas de luxo me ajudam a me comunicar com a minha autoidentidade", a prevalência ocorreu no gênero masculino. Já para as demais variáveis significativas ("As marcas de luxo ajudam a me definir"; "As marcas de luxo me 
ajudam a me enquadrar em situações sociais importantes"; "Eu gosto de ser visto usando marcas de luxo"; e "Eu gosto de quando as pessoas sabem que eu estou usando uma marca de luxo"), a prevalência foi do gênero feminino, o que significa que há uma predominancia desse grupo no consumo de produtos de luxo.

Assim como ocorreu na vertente do materialismo, os indivíduos que se destacaram na análise no que tange à renda foram aqueles que ganham entre três e seis salários mínimos, ratificando os achados nas pesquisas da SPC Brasil e Meu Bolso Feliz (2015). Queiroz (2014) aborda que um dos mitos que permeiam essa questão é que o consumo de produtos de luxo falsificados ocorrem entre as pessoas de menor poder aquisitivo. Já em um estudo realizado por Sales (2010), ele concluiu que o consumo desses produtos não ocorrem apenas entre indivíduos de baixa classe social. Umas das justificativas que permeiam esses achados é o de que esses consumidores de classes mais altas adquirem os produtos falsificados pelo fato de que isso foge da percepção alheia. Como eles possuem poder aquisitivo para adquirir o original, as pessoas não julgariam que aquele produto fosse falso.

No que diz respeito à escolaridade, as variáveis siginificativas foram: "As marcas de luxo me ajudam a me comunicar com a minha autoidentidade" ( $p=0,032)$; e "As marcas de luxo me ajudam a me enquadrar em situações sociais importantes" ( $p=0,008)$. Ao realizar a tabela cruzada, identifica-se que indivíduos que possuem nível superior estão mais propensos a se encaixarem nas duas situações. A faculdade é um tempo de transição, em que os jovens passam a ter uma maior independência dos pais, atingem a maioridade e, por isso, sentem-se livres para explorar novos desafios a partir de então. É nessa época que eles tendem a desenvolver sua autoidentidade, e, a partir disso, escolher os grupos sociais aos quais querem se integrar. As marcas de luxo se tornam peça fundamental de apoio para esse desenvolvimento para muitos deles.

Sobre o estado civil, os solteiros se apresentaram como o grupo mais propenso a usar as marcas de luxo como um símbolo de status social $(p=0,023)$ e como forma de serem incluídos em situações sociais importantes $(p=0,007)$. As pessoas solteiras, por serem mais livres em diversas áreas da vida, em tese, gostam de abrir novos horizontes e buscam aumentar o seu status perante o público com o qual interagem. Com a facilidade do crédito e do parcelamento, a compra de produtos de luxo originais tem sido uma realidade crescente na vida dessas pessoas que, independente da renda que possuem, veem que é possível ter o prazer de andar nas ruas com bens luxuosos, mesmo que isso lhes incorra em sacrifícios para poupar dinheiro em outras situações de sua vida.

Sobre a H3 (Há associação entre o materialismo e o consumo de produtos de luxo falsificados), procedeu-se a correlação de Pearson, apresentando os seguintes resultados no quadro 1.

Quadro 1 - Correlação entre os construtos.

\begin{tabular}{|l|c|c|c|c|c|c|}
\hline \multicolumn{2}{|c|}{ Dimensões da compra de produtos falsificados } & $\begin{array}{c}\text { Função } \\
\text { expressiva de } \\
\text { valor }\end{array}$ & $\begin{array}{c}\text { Função de } \\
\text { ajustamento } \\
\text { social }\end{array}$ & Felicidade & Centralidade & Sucesso \\
\hline $\begin{array}{l}\text { Função expressiva } \\
\text { de valor }\end{array}$ & $\begin{array}{c}\text { Pearson } \\
\text { Correlation }\end{array}$ & 1 &, 000 &, $328^{* *}$ &, $214^{* *}$ &,$- 188^{* *}$ \\
\cline { 2 - 7 } & Sig. (2-tailed) & & 1,00 &, 000 &, 000 &, 000 \\
\hline $\begin{array}{l}\text { Função de } \\
\text { ajustamento social }\end{array}$ & $\begin{array}{c}\text { Pearson } \\
\text { Correlation }\end{array}$ &, 000 & 1 &, $466^{* *}$ &, $152^{* *}$ &, 050 \\
\cline { 2 - 7 } & Sig. (2-tailed) & 1,00 & &, 000 &, 000 &, 216 \\
\hline
\end{tabular}

Fonte: Elaborado pelos autores (2016).

A partir dos resultados, pode-se inferir que houve correlação entre o materialismo e a compra de produtos falsificados, fato que corrobora com Kozar e Marcketti (2011), que afirmam que, como a compra de produtos não originais é uma atividade de consumo atrelada ao prestígio da marca e da imagem, parece aceitável, então, que exista uma relação entre o materialismo e o comportamento de compra de bens de produtos falsificados. 
A função expressiva de valor, umas das dimensões que compõe a escala de consumo de produtos de luxo falsificados, apresentou correlação com as três dimensões do materialismo. Para a primeira dimensão, felicidade $(r=0,328)$, média mais alta nesta pesquisa, os resultados sugerem que, à medida que os pesquisados adquirem produtos falsificados, maior a tendência de eles buscarem nesses bens a felicidade e o bem-estar que procuram. Embora pesquisas mostrem que produtos falsificados são vistos de forma negativa quanto à sua qualidade e confiabilidade (PENZ; STOTTINGER, 2008), e que podem causar uma impressão positiva ou negativa por parte da sociedade em relação ao consumidor que o adquire (TERRES et al., 2010), os consumidores estudados parecem ignorar essa realidade, estando dispostos a comprometer sua imagem para saciar seus desejos consumistas, acreditando que, assim, vão estar felizes e satisfeitos com os bens adquiridos.

A correlação entre função expressiva de valor e centralidade apresentou coeficiente $r=0,214$. Esses números possibilitam pressupor que, ao passo em que consumidores compram produtos falsos para que, por meio deles, venham a expressar seus valores, eles fazem de suas posses algo central em sua vida. Esse resultado corrobora com estudos realizados por Queiroz (2014), que pesquisou sobre a relação entre materialismo e consumo de produtos de luxo falsificados no segmento jovem em Santa Catarina. Pelas diferenças entre produtos estarem cada vez mais imperceptíveis (TURUNEN; LAAKSONEN, 2011), as pessoas parecem estar se valendo de bens contrafacionados para mostrar seus valores à sociedade, especialmente os jovens solteiros, os quais se destacaram nas pesquisas como potenciais consumidores desses produtos.

No que tange à dimensão sucesso, a função expressiva de valor encontrou o coeficiente $r=-0,188$, apresentando uma baixa correlação negativa. Esses dados mostram que, mesmo quando os consumidores investigados adquirem bens falsificados para expressarem seus valores, eles não tendem a julgar os outros e a si mesmo em função da quantidade e qualidade de suas posses, nem estão interessados em olhar para o seu sucesso a partir dos bens acumulados. Acredita-se que a maioria dos pesquisados compre produtos falsos com conhecimento de causa (GROSSMAN; SHAPIRO, 1988), ou seja, sabendo da realidade do preço, da qualidade e do status que aqueles bens possuem em comparação à marca original, o que lhes tem conscientizado a adotar uma postura modesta, a fim de que não venham julgar ninguém por possuir uma quantidade maior de produtos do que as outras pessoas.

Outro componente pertencente às dimensões da compra de produtos falsificados é a função de ajustamento social, o qual apresentou correlação com o seguinte construto: felicidade $(r=0,466)$. É válido ressaltar que a função de ajustamento social está atrelada à busca das pessoas pelas marcas de luxo, sendo um reflexo de poder aquisitivo. Em outras palavras: "você vale o que você tem" (QUEIROZ, 2014). Dos achados desta pesquisa pode-se deduzir que, quanto mais os consumidores pesquisados compram bens falsificados para se agregarem a diferentes grupos sociais e conseguem ser aceitos por eles, maior é sua sensação de felicidade e bem-estar com a utilização desses produtos. Belk (1988) afirma que os bens ajudam as pessoas a se definirem. Para ele, pessoas constantemente escolhem os grupos e subgrupos sociais com os quais querem interagir e a cultura de que fazem parte por meio de suas posses. Por meio desse processo de definição, à medida que os indivíduos mudam seus grupos sociais, há uma necessidade de mudar seus desejos, fazendo com que o consumo de produtos falsificados se torne uma realidade sem fim.

Sob o aspecto da centralidade, mediante sua correlação com a função de ajustamento social ( $r=$ $0,152)$, sugere-se que os indivíduos que consomem produtos de luxo falsificados a fim de serem aceitos em determinados grupos sociais, quando atingidos seus interesses, fazem desses bens algo central em sua vida. É provável, portanto, que, quando um consumidor, participante dessa pesquisa, é aceito em qualquer grupo social de seu interesse, aumenta sua tendência consumista por bens contrafacionados por observar que a compra desse produto facilitará seu acesso por chamar a atenção daquelas pessoas com quem quer estreitar laços. 


\section{Conclusão}

Esta pesquisa buscou investigar a relação entre o materialismo e o consumo de produtos falsificados em cidades do estado do Rio Grande do Norte. Com a finalidade de testar as hipóteses pré-estabelecidas, o estudo averiguou, com relação à H1 (As variáveis gênero, faixa etária, renda, escolaridade, e estado civil contribuem para o índice de materialismo), que as mulheres possuem mais tendências materialistas do que os homens. Já com relação à faixa etária, identificou que os indivíduos entre 21 a 30 anos se sobressaíram em todas as variáveis analisadas. No que tange à renda, as evidências mostraram que os indivíduos que possuem renda de três a seis salários mínimos (classes $C$ e $D$ ) tendem a ser mais materialistas. Sobre a escolaridade, os indivíduos que mais se destacaram foram os que possuem nível superior e, no que diz respeito ao estado civil, os solteiros foram a categoria mais representativa de correlação com a dimensão materialismo.

A fim de testar a hipótese H2 ( As variáveis gênero, faixa etária, renda, escolaridade, e estado civil contribuem para o consumo de produtos de luxo falsificado), com relação à faixa etária, não se obteve nenhuma variável significativa. Sobre o gênero, a prevalência foi do gênero feminino; e, no que se refere à renda, as evidências apontaram que as pessoas que ganham entre três e seis salários mínimos tendem a consumir mais produtos falsos. Do mesmo modo da dimensão materialismo, quanto à escolaridade e ao estado civil, os indivíduos que apresentaram maior correlação foram os que possuem nível superior e os solteiros.

Sobre a H3 (Há associação entre o materialismo e o consumo de produtos de luxo falsificados), os resultados permitiram inferir que houve correlação entre os dois construtos. Percebeu-se que a "função expressiva de valor" apresentou correlação com as três dimensões do materialismo. Já a dimensão "função de ajustamento social" se correlacionou com os construtos "felicidade" e "centralidade".

Os resultados apresentam relevância instrumental no tocante ao processo gerencial, pois o estudo desses números obtidos mediante survey aplicada na presente pesquisa pode gerar muitos insights para as empresas, principalmente no que tange as áreas do marketing e segmentação de mercado, dentre outros aspectos organizacionais. Tais resultados podem ser utilizados pelas organizações eservir de base para tomadas de decisão, adotando-se estratégias de marketing para alcançar diferentes públicos dentro das cidades do Rio Grande do Norte e de outros estados. Pode-se desenvolver ações, por exemplo, que busquem atrair a atenção dos consumidores masculinos, já que a pesquisa evidenciou o gênero feminino como prevalente no consumo de bens de luxo, assim como também que busquem atrairas pessoas idosas, que, na maioria das vezes, ainda mantêm um pensamento conservador e resistente quanto ao luxo. É importante observar também que é necessário tentar reduzir o consumo de bens falsificados por esses públicos. Estratégias como promoções, fortalecimento da qualidade, dentre outras, poderiam incentivar a preferência dos consumidores por bens de luxo originais.

Finalmente, é importante frisar as limitações deste trabalho. Destaca-se a diferença substancial no tamanho dos grupos comparados e a obtenção de respostas em sua maioria de indivíduos do sexo feminino e com faixa etária até 30 anos. Tal limitação, contudo, pode ser justificada pelo fato de se ter adotado uma amostra probabilística aleatória simples para análise dos dados em função de limitações de tempo e recurso. Em segundo lugar, registra-se que a pesquisa se limitou a residentes apenas das cidades do Rio Grande do Norte, em um corte transversal, não sendo recomendada a generalização dos resultados para as demais regiões do país. Sugere-se, portanto, o desenvolvimento de outras pesquisas que contemplem outras regiões e outras variáveis no que tange os fatores determinantes do consumo de produtos de luxo falsificados. Sugere-se ainda que a pesquisa seja aplicada no mercado internacional, a fim de fazer a comparação com os achados obtidos no Brasil. Enfatiza-se a necessidade de explorar mais o tema do ponto de vista empírico e conceitual devido sua complacência e atualidade.

\section{Referências}

BAIN \& COMPANY. Luxury goods worldwide market study, fall-winter 2014: the rise of the borderless consumer, 2014. Disponível em: < http://www.bain.com/bainweb/PDFs/Bain_Worldwide_ 
Luxury_Goods_Report_2014.pdf>.Acesso em: 12 abr. 2017.

BARBETTA, P. A. Estatística aplicada as ciências sociais. 2 ed. Florianópolis: UFSC, 2004.

BELK, R. W. Extended self in a digital world. Journal of Consumer Research. Chicago, v. 40, n. 3, p. 477-500, out. 2013.

Materialism: trait aspects of living in the material world. Journal of Consumer Research, [S,I], v.12, p. 265-280, 1985.

BIAN, X.; MOUTINHO, L. Counterfeits and branded products: effects of counterfeit ownership. Journal of Product \& Brand Management, [S,I], v.20, n.5, p.379-393, 2011.

CHAUDHRY, P. E.; STUMPF, S. A. Consumer complicity with counterfeit products. Journal of Consumer Marketing, [S,I], v. 28, n. 2, p.139-151, 2011.

CIB. Counterfeit Intelligence Bureau, 2011. Disponível em: <http://www.iccwbo.org/products-andservices/fighting-commercial-crime/counterfeiting-intelligence-bureau/>. Acesso em: 25 maio 2016.

CORRAR, L. J.; PAULO, E.; DIAS FILHO, J. M. Análise multivariada para cursos de administração, ciências contábeis, e economia. 1ª. ed. $7^{\text {a }}$. reimp. São Paulo: Atlas, 2014.

DODGE, H.R.; EDWARDS, E.A.; FULLERTON, S. Consumer transgressions in themarketplace: consumers' perspectives. Psychology \& Marketing, Michigan, v.13, n.8, p.821-35, Dez. 1996.

FERREIRA, J. B. et al. O mercado de luxo do Rio de Janeiro: uma análise da percepção das consumidoras cariocas. Revista de Administração MADE, Rio de Janeiro, v. 17, n.2, p. 66-84, maioago. 2013.

GIL, A. C. Como elaborar projetos de pesquisa. 4.ed. São Paulo: Atlas, 2010.

GROHMANN, M. et al. Relação entre materialismo e estilo de consumo: homens e mulheres com comportamento dispare?. Contaduría y Administración, México, v.57, n.1, p.185-214, maio 2012.

GROSSMAN, G; SHAPIRO, C. Foreign counterfeiting of status goods. Journal of Economics, [S.I], v. 103, n.1, p.79-100, 1988

HAIR JR., J. F. et al. Análise multivariada de dados. 6. ed. Porto Alegre: Bookman, 2009. 688 p.

HENNIGS, N.; WIRDMANN, K. P.; KLARMANN, C. Luxury brands in the digital age - exclusivity versus ubiquity. Marketing Review St. Gallen, [S.I], v. 29, n.1, p. 30-35, Feb. 2012.

JOUNG, H. Materialism and clothing post-purchase behaviors. Journal of Consumer Marketing, [S.I], v. 30 , n. 6 , p.530 - 537, 2013.

KASSER, T. The high price of materialism. Cambridge, Masachusetts: Bradford Books, 2002.

KOZAR, J. M.; MARCKETTI, S. B. Examining ethics and materialism with purchase of counterfeits.

Social Responsibility Journal, [S.I], v.7, n. 3, p.393-404, 2011.

LEE, M. W.; AHN, C.Y. Anti-consumption, materialism and consumer well-being. Journal of Consumer Affairs, [S,I], v.50, n.1, p.18-47, 2016.

MATTAR, F. N. Pesquisa de marketing: metodologia, planejamento. $6^{\text {a }}$ ed. São Paulo: Atlas, 2008.

NOGAMI, V. K. C.; GARBIM, J. G. U. A busca da ostentação por meio da falsificação: pesquisa com consumidores de alta e baixa renda. Diálogo, Canoas, n. 27, p. 125-140, dez. 2014.

NORUM, P.S.; CUNO, A. Analysis of the demand for counterfeit goods. J. Fashion Marketing and Management, [S.I], v.15, n.1, p.27-40, 2011.

OGDEN, H.; CHENG, S. Cultural dimensions and materialism: comparing Canada and China. Asia Pacific Journal of Marketing and Logistics, [S.I], v. 23, n. 4, p.431-447, 2011. 
PENZ, E.; STÖTTINGER, B. Original Brands and Counterfeit brands - do they have anything in common? Journal of Consumer Behavior, [S.I], v.7, p.146-163, 2008.

QUEIROZ, A. S. Materialismo e consumo de luxo falsificado no segmento jovem. 2014. 120f. Dissertação (Mestrado em Administração). - Universidade do Vale do Itajaí, Biguaçu - Santa Catarina, 2014.

REVISTA EXAME. A indústria do luxo agora invade o interior do Brasil. Disponível em: <http:// exame.abril.com.br/revista-exame/riqueza-e-luxo-para-exibir/>. Acesso em:12 abr. 2017.

RICHINS, M.L.; DAWSON, S. A consumer values orientation for materialism and its measurement: scale development and validation. Journal of Consumer Research, [S.I], v. 19, n. 3, p.303-316, 1992.

SALES, G. B. J. O consumo da pirataria na moda de luxo: o espelho de duas faces. 2010. 133f. Dissertação (Mestrado em Sociologia). - Universidade Federal da Paraíba, João Pessoa - Paraíba, 2010.

SANTOS, C. P.; FERNANDES, D. V. D. H. A socialização do consumo e a formação do materialismo entre os adolescentes. Revista de Administração Mackenzie, São Paulo, v. 12, n. 1, p. 169, fev. 2011.

SCHUSTER, M. S.; DIAS, V. V.; BATTISTELLA, L. F. Estressado? Vá às compras! - a investigação da compra compulsiva como estratégia de enfrentamento de Burnout.

Revista Ciências Administrativas, Fortaleza, v. 22, n. 2, p. 483-506, jul./dez. 2016.

SILVA, L. S.; PESSOA, L. A. G.; OLIVEIRA, R. C. A. Motivações para a compra de réplicas de bolsas LV. In: ENANPAD - ENCONTRO NACIONAL DOS PÓS-GRADUADOS EM ADMINISTRAÇÃO, 37., 2011. Rio de Janeiro, RJ, Anais... Rio de Janeiro, RJ. ANPAD, 2011. p.1-16.

SPC BRASIL E MEU BOLSO FELIZ. Consumo de produtos de luxo falsificados. Disponível em: $<$ https://www.spcbrasil.org.br/uploads/st_imprensa/estudo_spc_brasil_falsificados1.pdf>. Acesso em: 26 maio 2016.

STEVENSON, M.; BUSBY, J. An exploratory analysis of counterfeiting strategies: Towards counterfeitresilient supply chains. International Journal of Operations \& Production Management, [S.I], v. 35, Iss: 1, p.110-144, 2015.

TERRES, M. S.; CAVEDON, N. R.; SANTOS, C. P. "O que reluz, definitivamente, não é ouro": estudo sobre o consumo de réplicas de marcas de luxo. Revista Ciências Sociais em Perspectiva, Cascavel, v.9, n.16, p.1-25, jan.-jun. 2010.

TURKYILMAZ, C. A.; USLU, A.; DURMUS, B. Antecedents and outcomes of consumers' inward and outward environmental attitudes: evidence from turkey. Procedia - Social and Behavioral Sciences, [S.I], v.175, n. 12, p. 90-97, 2015.

TURUNEN, L. L. M.; LAAKSONEN, P. Diffusing the boundaries between luxury and counterfeits. Journal of Product \& Brand Management, [S.I], v. 20, Iss: 6, p.468-474, 2011.

VEER, E.; SHANKAR, A. Forgive me, father, for i did not give full justification for my sins: How religious consumers justify the acquisition of material wealth. Journal of Marketing Management, [S.I], v. 27, n. 5-6, p. 547-560, 2011.

VERGARA, S. C. Projetos e relatórios de pesquisa em administração. São Paulo: Atlas, 2013.

WANG, Y. Social stratification, materialism, post-materialism and consumption values: an empirical study of a Chinese sample, Asia Pacific Journal of Marketing and Logistics, [S.I], v. 28, n. 4, p.580-593, 2016.

WILCOX, K. H. S. S. Why do consumers buy counterfeit luxury brands? Journal Of Marketing

Research (JMR), [S.I], v.46, n.2, p. 247-259, 2009. 
WTO. World Trade Organization, 2014. Disponível em: <www.wto.org/english/thewto_e/glossary_e/ glossary_e.htm>. Acesso em: 25 maio 2016.

Submetido em: 02/09/2016

Aprovado em: 07/06/2017 